\title{
Cosmetics and Beauty Products Review
}

\section{Heyam Saad Ali*}

Professor, Department of Pharmaceutics, Faculty of Pharmacy, University of Khartoum, Sudan

*Corresponding Author: Heyam Saad Ali, Professor, Department of Pharmaceutics, Faculty of Pharmacy, University of Khartoum, Sudan.
Received: November 22, 2018

Published: June 30, 2020

(C) All rights are reserved by Heyam Saad Ali.

\section{Abstract}

The word "Cosmetics" is known to human race since ages. At the same time, desire to look good and attractive for every individual also can be identified as the psychological need having been given the upper place in hierarchy for ages. However, it will be relevant to understand the exact meaning of the word „cosmetic" from various sources at the outset.

Keywords: Cosmetics; Beauty; Hair Color

\section{Introduction}

Cosmetics are the articles that are meant to be applied topically for cleansing, beauty and attractiveness purposes. The used raw material should be:

- Highest quality, standardized, distilled or purified water.

- Tested under all conditions and shelf life.

Most people use cosmetic because it is safe, but adverse reactions occur in many cosmetics such as: deodorants, hair sprays, eye cream, hair color, dye lighteners, facial skin cream. Cosmetics include: Tooth paste, tooth powders, mouthwashes, nail polishes, face powder, cold and vanishing cream.

Properties of cosmetic

- Cleans, beautifies and alters the appearance.

- $\quad$ Adds fragrance.

- Stops the development of bad odor.

- It does not have any medicinal effect on the body.

Classification of cosmetics

Cosmetics are generally classified as follows:

- Based on product's functions.

- $\quad$ Based on product's use.

- $\quad$ Based on product's physical dosage form.

\section{According to their functions}

- Decorative function, e.g. Lipstick.

- $\quad$ Corrective function, e.g. Face powder.

- Protective function, e.g. Dry cream.

- Therapeutic function, e.g. Hair preparation.

According to their use

- $\quad$ For the skin, e.g. Powder, cream and makeup.

- $\quad$ For the hair, e.g. Shampoo, hair dressing.

- For the nails, e.g. Nail polish, manicure preparation.

- $\quad$ For the teeth and mouth, e.g. Mouth washes.

- Borderline and kindred product, e.g. Eye product, insect repellent.

\section{According to their physical natures}

- $\quad$ Aerosols, e.g. Hair set.

- $\quad$ Cakes, e.g. Rouge compact.

- Emulsion, e.g. Cold and vanishing cream.

- Jellies, e.g. Hand jelly.

- Mucilage's, e.g. Hand lotion.

- $\quad$ Oils, e.g. Hair oil. 
- $\quad$ Pastes, e.g. Tooth paste.

- $\quad$ Powders, e.g. Face powder.

- $\quad$ Soaps, e.g. Shampoo soaps.

- Solutions, e.g. Lotion.

- $\quad$ Sticks, e.g. Lipsticks.

- $\quad$ Suspension, e.g. Liquid powder.

Dentifrices

- Dentifrices are preparations meant to be applied to the teeth such as toothpaste and tooth powder.

- They include drug such as antibiotics, fluoride, ammoniated material and other substances, which bring changes in the oral cavity then these preparations, can be called drugs.

Ingredients used in dentifrices

- Polishing agent (Abrasives): Abrasives, which are also known as polishing agent, are used to remove debris and residual stains from the teeth and for polishing the tooth surface. The commonly used abrasives include precipitated calcium carbonate, tribasic calcium phosphate.

- $\quad$ Surface-active agent (Detergents): Surface-active agents are added to enhance the action of polishing agents by wetting the teeth.

- Humectant: A humectant is added to tooth paste, which will keep it moist and will not allow the paste to become dry.

- Binder: Binder is added to keep the solid and liquid united and also maintain the consistency.

- Flavoring agent: It is one of the most important ingredients of dentifrices and also important because choice of flavor varies from individual to individual.

- Sweetening agent: It is added to dentifrices to impart sweet taste to the preparation.

- Preservatives: Should be included in the toothpaste to preserve its quality and stability.

- $\quad$ Therapeutic agents: They are included in medicated tooth pastes in order to check dental disease and to remove bad smell but all toothpaste's do not contain these agent, e.g. Fluoride.

Toothpaste or tooth powder should have the following quality

- When applied to the teeth it must remove foreign particle.

- It must be nontoxic.

- It must be properly flavored and sweetened.

- It must leave the mouth with a refreshing after-taste.
Example of tooth paste formulation

- $\quad$ Precipitated chalk, light.

- Colloidal clay.

- Glucose.

- Glycerin.

- Water.

- Methyl paraben.

- Peppermint oil.

\section{Facial cosmetics}

Face powder

It is a cosmetic preparation, which is applied to the face by means of a powder puff.

- Face powder is not only used by women but men also use colored face powder after-shaves.

- The various raw materials used in the formulations of face powders include talc, kaolin, calcium carbonate, magnesium carbonate, zinc stearate, magnesium stearate, calcium silicate, color and perfume.

\section{Characteristics of face powder}

- It should be very fine and should not have any gritty particle.

- $\quad$ The ingredients should be evenly distributed.

- It should be nontoxic and non-irritant to the skin.

- It should be chemically and physically stable.

- It should spread easily and adhere to the skin.

- It should have good adsorbing property.

- $\quad$ It should remove shine from face.

- It should cover minor imperfections of the face and should not appear as paint.

- It should look natural.

- It should not dust off in a few minutes and make re-powdering necessary.

Formula for body powder

- $\quad$ Talc.

- $\quad$ Zinc stearate.

- Boric acid

- $\quad$ Perfume. 


\section{Compact powder}

It is simply a face powder, which is pressed in the form of a cake and is applied on the face with a powder puff.

Formula for compact powder

- Talc.

- Zinc oxide.

- Kaolin.

- $\quad$ Titanium oxide.

- Calcium carbonate.

- $\quad$ Rice starch.

- Binder solution.

- Perfume sufficient quantity.

Marketed Compact powder

- Lakme.

- Gala of London.

- $\quad$ Tips and Toes.

- Clear Touch.

- $\quad$ Ravon 2-way cake.

Rouges

It is a preparation, which is applied to the cheeks for enhancing the face beauty and to impart and to stimulate the rosy freshness of the young and healthy skin. Various types of rouges such as liquid, cream and solid rouges are available in numerous shades. Solid rouges are stable and easy to apply. Dry compact rouge is applied by means of a puff.

\section{Cold creams}

They are cosmetic preparations, which are intended to be applied topically to the face or on the body surface, for the purpose of cooling and hydrating effects. The principle of their formulation is based upon the emulsification of emulsifying agent to water and oils using certain techniques.
Formula for cold water

White beeswax, stearic acid, wool fat, liquid paraffin, terpineol, tri-ethanolamine, propylene glycol, water and perfume in sufficient quantity.

\section{Procedure}

Melt stearic acid, white beeswax, and wool fat on water bath. Then add terpineol, separately warm water to almost same temperature as that of melted oils and add tri-ethanolamine. Incorporate warmed aqueous liquid to the melted oils and stir continuously so as to get a creamy emulsion. Then add propylene glycol in which perfume has been mixed. Stir thoroughly until a smooth cream is formed and it cools down to room temperature.

Marketed cold creams

- $\quad$ Nivea.

- Ponds.

Vanishing creams

They are oil-in-water emulsions, the principle of their formulation is based upon emulsification of both stearic acid and water using alkaline substance such as sodium hydroxide, potassium hydroxide, and borax, tri-ethanolamine, etc. glycerin is also added. Stearic acid is the most important constituent of vanishing creams hence a good quality triple pressed stearic acid should be selected.

\section{Formula for vanishing cream}

Stearic acid, glycerin, lanolin, tri-ethanolamine, water, preservative and perfume in sufficient quantity.

\section{Procedure}

Melt stearic acid and lanolin. Separately mix water, glycerin and tri-ethanolamine and warm to almost the same temperature as that of the melted substances. Mix the two with continuous stirring. Add the preservative and perfume. Mix thoroughly until a uniform product is obtained. 
Eye make-up

- $\quad$ Eyebrow pencils: They are hard crayons, usually black and are used for darkening the eyebrows. The eyebrow pencils contain a high proportion of waxes to make them hard so that they can be molded as a thin stick and sharpened to a point.

- Mascara: It is a dark pigmented preparation used on the eyelashes and eyebrows to darken and thicken their appearance. It is applied with a brush.

- Eye shadow: Is used to give a color round the eyes and is applied to the eyelids. Eye shadows are prepared in wax bases in the form of creams, emulsions, sticks, and loose powders or as compressed powders.

Mascara should have the following qualities

- It must be nontoxic.

- It must be non-irritating to the eyes.

- It must not run, cake or cause eyelashes to stick together.

- It should be applied easily and evenly.

Qualities of lipsticks

They are used to give bright, glow and color to the lips. They should be:

- $\quad$ Nontoxic and non-irritating.

- $\quad$ Free from gritty particles.

- $\quad$ Easily applicable and easily removable if need arises.

- Have a good odor.

- Give shiny and smooth appearance.

- Moist and not dry on storage.

- $\quad$ Free from sweating.

- Maintain its lip color long after its application.

- $\quad$ Flexible and firm not to break during use.
Shaving media

They are really not the cosmetics for the hair but they are used to remove unsightly hair particularly from men's faces. Women also use them in limited amounts to remove hair from legs, under the arm and other conspicuous places with or without the help of a razor.

Various types of shaving media include:

- $\quad$ Pre-shave products: e.g. Beard softeners and pre-electric shaving lotions.

- $\quad$ Shaving products: They include brushless shaving creams, lather shaving creams and shaving soaps.

- $\quad$ After shave products: They include lotions and gels used to refresh the skin after-shave.

\section{Lather shaving creams}

They are semisolid preparations, which are used by men to help in removing the hair from the face. Glycerin is extensively used as humectant in these types of shaving creams. The ingredients commonly used in the preparation of shaving creams include: stearic acid, coconut oil, olive oil, peanut oil, caustic soda, caustic potash, glycerin, alcohol, lanolin, borax, boric acid, propylene glycol, aromatic water and water. Coloring and flavoring agents' maybe added according to choice and depending on the nature of other ingredients.

Qualities of a good lather shaving cream

- It should be non- irritating to the skin.

- It should not change its viscosity according to temperature.

- It should be smooth, soft and non-lumpy.

- It should have good wetting properties.

- It must produce rich lather composed of small bubbles that do not dry on the face too rapidly.

- Only small quantity of cream should be required to produce good lather, i.e., it should be economical.

- It should be non-corrosive to the razor blade and easily rinsed from the razor and face. 
Formula for lather shaving cream

- $\quad$ Stearic acid.

- $\quad$ Coconut oil.

- $\quad$ Potassium hydroxide.

- $\quad$ Sodium hydroxide.

- Glycerol.

- Water.

- $\quad$ Preservative, sufficient quantity.

- $\quad$ Perfume, sufficient quantity.

Antiperspirants and Deodorants

Bad odor emitted by the body of both men and women is a great problem. So the substances which are used to overcome this bad smell are known as antiperspirants and deodorants. The sweat glands secrete perspiration, which varies from person to person.

- Antiperspirants and deodorant are cosmetic products, which are used to reduce underarm and body odor.

- Antiperspirants inhibit the flow of perspiration and deodorants inhibit the formation of malodor in perspiration by suppressing bacterial growth or cover the malodor with more pleasing one.

- Antiperspirants and deodorants are available as clear liquids for direct, spray or aerosol application, powder sprays, sticks, creams and lotions.

- The liquid antiperspirants consist of an aqueous or hydro alcoholic solution of an astringent salt to which a small amount of humectant, a perfume, a dispersing agent for the perfume and a deodorant is added.

Formula for deodorant powder

- $\quad$ Salicylic acid

- Boric acid.

- Talc.

- Zinc stearate.
Formula for liquid antiperspirant

- Alcohol.

- $\quad$ Propylene glycol.

- Hexachlorophene.

- Aluminium chlorohydroxide.

- Water.

- $\quad$ Perfume, sufficient quantity.

Shampoos

- Shampoos it is a preparations used to remove both hydrophilic and hydrophobic grease, dirt and debris from the hair and scalp without harm and adverse reactions.

- Generally they are prepared water soluble ingredients into water phase, then continuous mixed and stirring with hydrophobic substance melted phase with addition of suitable type surfactant/surfactants.

- Addition of substances to improve the functions appearance acceptability such as coloring, perfumes, glow etc. should be at the end.

Properties of a shampoo

- It should be effective in small amounts.

- It should be nontoxic non-irritant and should not damage the skin and sensitive organs like eyes if accidentally come in contact with them.

- It should produce adequate foam in soft as well as hard water.

- It should give pleasant flavor after its use.

- It should be easily washable with water.

- It should leave the hair lustrous, soft and manageable.

\section{Different forms of shampoos}

- Clear liquid shampoos.

- Baby shampoos.

- $\quad$ Medicated dandruff shampoos. 
- Soap shampoos.

- $\quad$ Liquid cream or lotion shampoos.

- Powder shampoos.

- Gel shampoos.

- $\quad$ Cream or paste shampoos.

Additives used in shampoos

- Opacifiers.

- $\quad$ Solubilizing Agents.

- $\quad$ Thickening Agents.

- Conditioning Agents.

- Preservatives.

Marketed shampoos

- $\quad$ Clinic.

- Sunsilk.

- $\quad$ Park Avenue Bear shampoo.

- Lakme.

- $\quad$ Ultra Doux.

Hair preparations

Hair dressings

They are products used for this purpose were homemade commonly prepared with wines, herbs, animal and plant bi- products but now a days along with homemade products with good results are introduced in the market the demand of which is increasing day by day.

Characteristics of a good hair dressing

- It should have good grooming action.

- It should provide luster to the hair without greasiness.

- It should nontoxic to the skin.

- It should provide some degree of hair conditioning.

- It should provide anti-dandruff action.

- It should have good wetting action.

\section{Brilliantines}

Brilliantines are used to impart luster to the hair and also for keeping the hair in place.

Hair conditioners

Hair conditioners are used to make the hair manageable, glossy and of soft texture they are generally used for those hair which are damaged by too frequent shampooing, hair straighteners, bleaching and dyeing

\section{Hair tonics}

Hair tonics are the preparations, which are applied to the hair for curing baldness, relieving oily or dry skin and to prevent or cure dandruff.

Hair-waving and hair-straightening preparations

Men and women had a quest to beautify their hair by one way or the other. Therefore hair waving and straightening products are prepared.

Hair dyes

They are hair Coloring products. They are classified according to the duration of action as temporary, semipermanent or permanent dyes.

Coloring products are classified as follows

- $\quad$ Bleaching agents.

- $\quad$ Temporary coloring agents.

- Permanent coloring agents.

- Natural organic dyes.

Characteristics of a hair dye

- It should be non-irritating to the hair and skin.

- It should be nontoxic.

- It should be able to color the hair shaft without damaging it.

- It should be stable and should not change its color when exposed to air, sunlight, shampoo or hair conditioning agents. 
Marketed hair dyes

- Godrej permanent liquid hair dye.

- Kesh kala hair darkner.

- $\quad$ Tru-tone gel.

- Wondrex cream hair dye.

- $\quad$ Bigen hair dye.

Depilatories (Hair Removers)

They are used to soften unsightly human hair so that it can be easily removed by wiping or rinsing a short time after application.

Qualities of a good depilatory

- It should complete its action within 2-5 minutes and during this period it should make the hair soft, swelled and dispersed and removed by applicator.

- It should be nontoxic and non-irritant to the skin.

- It should be easy to apply.

- It should be economical to use.

- It should be elegant, odorless or pleasantly flavored.

- It should remain stable in the container.

Marketed hair removers

- Anne French.

- Lakme.

\section{Antidandruff preparations}

Dandruff: is a scaly fungal disease of the scalp, therefore, antifungal therapeutic agents are mostly used. However for scales generally, salicylic acid, sulphur in low concentrations are used [1-16].

\section{Bibliography}

1. FDA/CFSAN. Is it a Cosmetic, a Drug or Both (or is it Soap?). U.S. Food and Drug Administration, Centre for food safety and applied nutrition, Office of cosmetics and colors fact sheet (2002).

2. Dooley TP. Is there room for a moderate level of regulatory oversight? In: Hori W, editor. Drug discovery approaches for developing cosmeceuticals: advanced skin care and cosmetic products. Southborough: IBC Library Series (1997).
3. Balch PA and Balch JF. In: Prescription for nutritional healing. 3rd ed. Vonore: Avery Publishing Group (2000).

4. Turkington CA and Dover JS. In: The encyclopedia of skin and skin disorders. $2^{\text {nd }}$ edition. Facts on file (2002).

5. Tiainin Pauliina. "Marketing Male Cosmetics: A review of Lumene for men products success to date and ideas for improvement". Master's thesis, Helsinki Metropolia University, Finland (2010).

6. Pullar JM., et al. "The roles of vitamin C in skin health". Nutrients 9 (2017).

7. Madison KC. "Barrier function of the skin: "La raison d'etre" of the epidermis"”. Journal of Investigative Dermatology 121 (2003): 231-241.

8. California Safe Cosmetics Program Product Database. http:// safecosmeticsact.org/search/EWG's Skin Deep Cosmetics Database www.cosmeticsdatabase.com, mobile app available The Good Guide, www.goodguide.com, mobile app for iPhone and Android with bar scanner Information about ingredients and the industry Cosmetic Ingredient Review.

9. De Groot AC. "Labelling cosmetics with their ingredients". British Medical Journal 300 (1990): 1636-1638.

10. De Groot AC., et al. "Unwanted effects of cosmetics and drugs used in dermatology, $3^{\text {rd }}$ edition" (1994).

11. Guin JD. "History, manufacture, and cutaneous reactions to perfumes". In: Frost P, Horwitz SW (eds) Principles of cosmetics for the dermatologist. Mosby, St Louis (1982): 111-129.

12. Matthieu L and Dockx P. "Discrepancy in patch test results with wool wax alcohols and Amerchol $₫$ L-101". Contact Dermatitis 36 (1997): 150-151.

13. Martin M Rieger. Harry's Cosmeticology, Publisher: Chemical Publishing Company; 8th edition (2000).

14. Schlossman M. The Chemistry and Manufacture of Cosmetics. Allured's Publishing Corp., USA (2001).

15. Schueller R and Romamouski P. Cosmetics and Personal Care. Allured's Publishing Corp., USA (1999). 
16. MS Balsam and Edward S. Cosmetics: Science and Technology. 2nd Edition. Krieger Publishing Company, Malabar, Florida, USA (1992).

\section{Assets from publication with us}

- Prompt Acknowledgement after receiving the article

- Thorough Double blinded peer review

- Rapid Publication

- Issue of Publication Certificate

- High visibility of your Published work

Website: www.actascientific.com/

Submit Article: www.actascientific.com/submission.php

Email us: editor@actascientific.com

Contact us: +919182824667 